Editorial

\title{
Social Inclusion and Multilingualism: Linguistic Justice and Language Policy
}

\author{
Zsombor Csata ${ }^{1,2, *}$ and László Marácz 3,4 \\ ${ }^{1}$ Centre for Social Sciences, Hungarian Academy of Sciences, 1097 Budapest, Hungary; E-Mail: csata.zsombor@tk.mta.hu \\ 2 Faculty of Sociology and Social Work, Babeș-Bolyai University, 400604 Cluj Napoca, Romania \\ ${ }^{3}$ Faculty of Humanities, University of Amsterdam, 1012 CX Amsterdam, The Netherlands; E-Mail: I.k.maracz@uva.nl \\ ${ }^{4}$ Department of International Relations, L. N. Gumilyov Eurasian National University, 010000 Astana, Kazakhstan \\ * Corresponding author
}

Submitted: 17 December 2020 | Published: 14 January 2021

\begin{abstract}
Multilingual or linguistically heterogeneous societies are increasing around the globe. Socio-political processes, like Europeanization and globalization, are responsible for this expansion. Universal norms and standards for language use and identity are spreading, mediated by international organizations and charters. In this view, multilingualism can be seen as a challenge to national social cohesion, though it remained undisputed before the development of global multi-level governance. In many places, languages of traditional territorial minorities have been recognized and given official status, leading in some cases to new forms of local, regional, and national governance. Furthermore, the proliferation of multilingualism is boosted by a variety of forms of mobility, where mobility is understood as physical migration or new forms of virtual mobility connected to digital networks. Mobility in this sense underpins the linguistic and transnational identity of the migrants who bring new languages with them. One of the questions in need of analysis is the circumstances and conditions that lead to the inclusion/exclusion from society of specific linguistic groups with shared linguistic features. This thematic issue wants to address the apparent schism between multilingualism and social inclusion as well as the language policy and planning pursued by supranational institutions, states, and societal organizations in their efforts tackle it. In this issue, the focus of study of linguistically diverse societies will be on the closely interrelated dependencies which impact language policy and planning.
\end{abstract}

\section{Keywords}

communication strategies; economy of language; language policy; linguistic justice; mobility; multilingualism; social inclusion

\section{Issue}

This editorial is part of the issue "Social Inclusion and Multilingualism: The Impact of Linguistic Justice, Economy of Language and Language Policy" edited by László Marácz (University of Amsterdam, The Netherlands / L. N. Gumilyov Eurasian National University, Kazakhstan) and Zsombor Csata (Babeș-Bolyai University, Romania / Hungarian Academy of Sciences, Hungary).

(C) 2021 by the authors; licensee Cogitatio (Lisbon, Portugal). This article is licensed under a Creative Commons Attribution 4.0 International License (CC BY).

\section{Introduction}

In the context of globalization and its ensuing superdiversity, creating fair and effective linguistic governance is a very complex challenge and there are no 'one size fits all' solutions. Several attempts have been undertaken so far to categorize and to create comprehensive typolo- gies of these strategies. One of these initiatives is the toolkit for multilingual and transnational communication (henceforth referred simply as the Toolkit; Jørgensen, 2011) which describes four communicative strategies that can be used in situations where speakers of different mother tongues converse together. These are the English as a lingua franca, the use of a regional lingua franca, 
receptive multilingualism and code-switching (Marácz, 2018). A Toolkit approach can be developed and implemented in a number of ways. First, it can inspire a fundamental rethinking and reorientation of the traditional 'foreign language' field in education systems. Its philosophy can also be fitted into the framework of citizenship courses for migrants and other newcomers, as well into the development of adult education in general, as part of a life-long learning concept. The European language policy recommendations (Commission of the European Communities, 2003), for instance, the " $1+2$ " Barcelona formula for language learning, should be accommodated by the Toolkit, which is a more complex containment strategy to guarantee that global English and other multilingual and transnational communication strategies do not limit but rather support mobility and inclusion.

A variety of strategies presented above are critically evaluated by the authors of this issue. Most of these policies propose multilingual solutions relying on actors being committed to the protection and promotion of cultural diversity based on the principles of fairness and dignity-objectives which are, however, often neglected by the utility-based hierarchization of languages as a result of the pressure from neoliberal governmentality in education and in public management. Another set of solutions offered by the authors in this issue to address the schism between multilingualism and social inclusion revolve around the use of a lingua franca in communication. English is on the rise as a global lingua franca, but there are concerns that it is not a perfect solution to avoid creating a range of asymmetries and hierarchies in linguistically diverse societies. Furthermore, there is uncertainty as to whether global English is adequate to create a more just and fairer world. Alternatives involving other lingua francas (Esperanto, Russian, etc.) are offered. Below, these solutions are presented in more detail through the lenses of the authors and their case studies.

\section{Multilingual Solutions}

Marketization and neoliberal governmentality have an increasing impact on how linguistically diverse societies operate. The dominance of neoliberal market principles in large parts of the world might result in the proliferation of multilingualism and linguistically diverse societies, but it hardly leads to more linguistic justice, mostly because of negative externalities stemming from individual decisions regarding the provision of language-related goods (Gazzola, Wickström, \& Templin, 2018, p. 34).

Countries promoting multilingual solutions, as evidenced by most of the articles in this issue (i.e., Austria, Scotland, and more recently also in Poland) largely acknowledge that there is a need for coordinated action from the governments to deal with this issue, and the public sector has a crucial role to play in this process. However, the effectiveness of public intervention is hampered by the fact that linguistic policies on education and public services themselves are set to increasingly follow the rules of a chronically underfunded new public management, organized along with the neoliberal principles of efficiency.

Signs of neoliberal governmentality have already emerged in the underlying ideologies of language policymaking. In this respect, the study of the Polish Language Council is eloquent (Hordecki \& Wallas, 2021). In the public narratives of the Council, the preservation of linguistic identity and the recognition of equal dignity is present alongside utility-based approaches, where language is perceived as a resource, an asset, a strategic device in the individual empowerment of people. This latter argument, intensively promoted and largely interiorized by public employees, including those in the education, reduces the value of linguistic diversity to the economic, pecuniary criterion. The author remarks that the Polish Language Council, as an epistemological community and an important actor in crafting the public debate on linguistic diversity, does not address the problem in sufficient depth. As a result, although they are not necessarily irreconcilable, the preservation of linguistic diversity and the utility-based approaches do often conflict and the recognition of equal dignity might be put at risk by a marketing of diversity (Kraus \& Kazlauskaitè-Gürbüz, 2014, p. 519), and efficiency might be prioritized over fairness (Grin \& Civico, 2018, p. 6). The dominance of economic imperatives lies also behind the argument that migration processes "do not pose any threat to the Polish language, but on the contrary-prove its power and attractiveness, highlighting the fact that Polish is becoming an international language in Central Europe" (as cited in Hordecki \& Wallas, 2021, p. 70)-an explicit reference to the legitimacy of international competition between languages. Tactical schemes built on reciprocity also show up in these arguments, i.e., teaching the language of immigrants in schools is a rewarding investment for the Polish government, as it increases the chances of the Polish diaspora gaining similar language rights in the Western countries that they emigrated to.

The prevalence of utility-based perspectives is perhaps the most eloquent in education policy. In Kanaki's (2021) article on Scotland, this problem is embodied in the dilemma of ligatures and options introduced by Kraus and Kazlauskaitè-Gürbüz (2014). The author argues that despite a more balanced and nuanced public discourse on language issues in Scotland, language skills offer 'options' rather than 'ligatures' for students to become "confident individuals, effective contributors and responsible citizens" (Kanaki, 2021, p. 21). As 'clients' of the education system they are required to make wise linguistic decisions for their personal careers. Meanwhile, the effective linguistic supply is quite hierarchical: In Scotland, as in Poland, international languages which offer greater employability and have higher market value are primarily offered for study even in the " $1+2$ " Language Approach scheme, to the detriment of regional/community languages. The name of the project 
"The Trinity of Languages" speaks for itself when it is about giving purposeful priorities to the global and regional lingua francas in Kazakhstan's education policies (i.e., English and Russian; see Zhumay et al., 2021).

Expectations about the entrepreneurial self are also pronounced when it comes to getting a job, but even in the context of super-diversity, the linguistic choices remain rather limited. An illustrative example in this respect is offered by Scheibelhofer, Holzinger, and Draxl (2021). In the offices of the Austrian Public Employment Service, knowledge of German language remains a tacit institutional expectation from the clients (mostly jobseekers), and in everyday interactions, multilingual communication is used only as an emergency solution. In addition, as a result of neoliberal management logic, the scope of the interventions is limited to the (re)integration of clients in the labor market. Meanwhile the facilitation of access to resources-regardless of their linguistic conditionality-remains secondary. This is also explained by the chronic underfunding and understaffing of these institutions, and by the consequent workplace pressures and alienation among employees. It is not a coincidence that most of the officials interviewed were surprisingly enthusiastic to take part in the study, being happy to have someone listen to them.

Some of these problems also appear in the Scottish public institutions examined by McKelvey (2021), many services reported similar practical challenges, such as difficulties in engaging sufficient numbers of interpreters and concerns about ensuring high-quality language support. Overall, the changes induced by neoliberal governance, due to the withdrawal of resources along with the internalization of client-based narratives on efficiency by the officials, create and maintain ad-hoc and inconsistent linguistic solutions in the public service.

Furthermore, the cases presented in this issue come from countries which have ratified the conventions created for the protection of minority languages, resulting in language policies and practices that are more likely to take the principles of dignity and fairness seriously. Even in this context, the situation is likely to become complicated in those places where a significant number of 'historical' minorities lives and actions of arbitrage should also take place along with the those targeting the protection and promotion of languages (Grin \& Civico, 2018). In such cases, the preservation of diversity is an even greater challenge; multiculturalism and multilingualism risk remaining empty phraseologies as long as (linguistic) differences are transformed into social and economic inequalities on the ground of utilitarian efficiency.

\section{Lingua Franca Solutions}

Globalization increases the frequency of contact with linguistic diversity, making multilingual and transnational communication strategies ever more relevant. One of these transnational communication strategies involves lingua franca communication. A lingua franca is a non-native bridge language used by interlocutors for communicative purposes, i.e., L1. Many commentators observe that English is the global lingua franca, although from a linguistic and sociolinguistic perspective the global spread of English raises significant problems. These problems arise in two different forms, depending on how this process is interpreted. If we view it as the spread of a standard variant of English, we may be facing a case of linguistic imperialism (Phillipson, 2006) with detrimental effects on linguistic justice. If, on the contrary, we view this process as the dissemination of something radically different from English, something often referred to, by its proponents, as English as a lingua franca (ELF). In the literature, ELF is indeed sometimes used to refer to English as spoken by non-native speakers, with morphological and lexical features that depart from those of standard English (for an extensive discussion of ELF see Gobbo \& Marácz, 2021). ELF advocates claim that these non-standard characteristics should be accepted. This would, so the argument goes, democratize international communication and strip English of its potentially imperialistic character. Such a view, unfortunately, suffers from serious limitations. However, Gobbo and Marácz (2021) argue that the vehicle of lingua franca communication between interlocutors involved should be rather a neutral language, which, like Esperanto, would guarantee maximal social inclusion.

For others, the issue of a global lingua franca is more than English-only and involves other lingua francas alongside global English. A number of languages of wider communication are already competing with global English for the status of (regional) lingua franca. In former parts of the Soviet Union, Russian is still being used as a regional lingua franca. Kazakhstan, a country within the former Soviet and the contemporary Russian orbit has even adopted an official trilingual policy, including an equally prominent status for native Kazakh, Russian, and English. Akkaliyeva, Abdykhanova, Meirambekova, Jambaeyva, and Tussupbekova (2021) convincingly argue in their contribution that Russian functions as a pivot between Kazakh and English in the translation of literary texts. Bayekeyeva, Tazhibayeva, Beisenova, Shaheen, and Bayekeyeva (2021) make a similar point in connection with multilingual thesauri for Kazakh industryspecific terms where Russian mediates between the Kazakh and English languages.

\section{Acknowledgments}

The research leading to these results has received funding from the National Research, Development and Innovation Office of Hungary, under grant agreement no. FK 125276.

\section{Conflict of Interests}

The authors declare no conflict of interests. 


\section{References}

Akkaliyeva, A., Abdykhanova, B., Meirambekova, L., Jambaeyva, Z., \& Tussupbekova, G. (2021). Translation as a communication strategy in representing national culture. Social Inclusion, 9(1), 5-13.

Bayekeyeva, A. T., Tazhibayeva, S. Z., Beisenova, Z. S., Shaheen, A. A., \& Bayekeyeva, A. T. (2021). Controlled multilingual thesauri for Kazakh industryspecific terms. Social Inclusion, 9(1), 35-44.

Commission of the European Communities. (2003). Communication from the Commission to the European Parliament, the Council, the European Economic and Social Committee and the Committee of the Regions, 2003: Promoting language learning and linguistic diversity: An action plan 2004-2006. Brussels: Commission of the European Communities. Retrieved from https://eur-lex.europa. eu/LexUriServ/LexUriServ.do?uri=COM:2003:0449: FIN:en:PDF

Gazzola, M., Wickström, B. A., \& Templin, T. (2018). Can the free market manage language diversity? In F. Grin, M. C. Conceição, P. A. Kraus, L. Marácz, Ž. Ozolin,a, N. Pokorn, A. Pym (Eds.), The MIME vademecum: Mobility and inclusion in multilingual Europe (pp. 34-35). Grandson: Artgraphic Cavin SA.

Gobbo, F., \& Marácz, L. K. (2021). Two linguas francas? Social inclusion through English and Esperanto. Social Inclusion, 9(1), 75-84.

Grin, F., \& Civico, M. (2018). Why can't language questions just be left to themselves? In F. Grin, M. C. Conceição, P. A. Kraus, L. Marácz, Ž. Ozoliṇa, N. Pokorn, A. Pym (Eds.), The MIME vademecum: Mobility and inclusion in multilingual Europe (pp. 30-31). Grand- son: Artgraphic Cavin SA.

Hordecki, B., \& Wallas, T. (2021). Members of the Polish Language Council on the problems of linguistic diversity and linguistic inclusion in Poland. Social Inclusion, 9(1), 63-74.

Jørgensen, J. N. (Ed.). (2011). A toolkit for transnational communication in Europe. Copenhagen: Faculty of Humanities, University of Copenhagen.

Kanaki, A. (2021). Multilingualism and social inclusion in Scotland: Language options and ligatures of the " $1+2$ language approach." Social Inclusion, 9(1), 14-23.

Kraus, P. A., \& Kazlauskaitè-Gürbüz, R. (2014). Addressing linguistic diversity in the European Union: Strategies and dilemmas. Ethnicities, 14(4), 517-538.

Marácz, L. K. (2018). Why should we combine different communication strategies? F. Grin, M. C. Conceição, P. A. Kraus, L. Marácz, Ž. Ozolina, N. Pokorn, A. Pym (Eds.), The MIME vademecum: Mobility and inclusion in multilingual Europe (pp. 102-103). Grandson: Artgraphic Cavin SA.

McKelvey, R. (2021). Language provision in the Scottish public sector: Recommendations to promote inclusive practice. Social Inclusion, 9(1), 45-55.

Phillipson, R. (2006). English-only Europe? Challenging language policy. London: Routledge.

Scheibelhofer, E., Holzinger, C., \& Draxl, A.-K. (2021). Linguistic diversity as a challenge for street-level bureaucrats in a monolingually-oriented organisation. Social Inclusion, 9(1), 24-34.

Zhumay, N., Tazhibayeva, S., Shaldarbekova, A. Jabasheva, B., Naimanbay, A., \& Sandybayeva, A. (2021). Multilingual education in the republic of Kazakhstan: Problems and prospects. Social Inclusion, 9(1), 56-62.

\section{About the Authors}
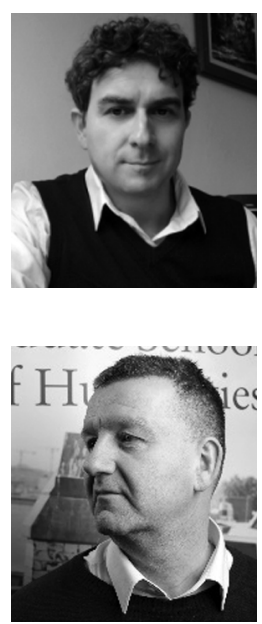

Zsombor Csata is an Economic Sociologist, a Research Fellow at the Centre for Social Sciences in Budapest, Hungary, and an Associate Professor at the Faculty of Sociology and Social Work, Babeș-Bolyai University, Romania. He has conducted several research projects on ethnicity, entrepreneurship, and regional development in Central and Eastern Europe. Lately, his research has been focused on the economic aspects of multiculturalism and the socioeconomics of language. He holds a PhD in Sociology at BBU and was a Fulbright Scholar at the University of Texas at Austin and a Julius Rezler Scholar at Indiana University in Bloomington.

László Marácz has defended his PhD dissertation in General Linguistics at the University of Groningen in 1989. Since 1992, he has been affiliated as a Senior Lecturer to the Department of European Studies at the University of Amsterdam. In 2015, László Marácz was awarded the title of Honorary Professor at the L. N. Gumilyov Eurasian National University in Nur-Sultan, Kazakhstan. He was Vice-Coordinator of the MIME consortium that won the European FP7-tender in 2013 on the "Multilingual Challenge for the European Citizen." 